\title{
Editorial
}

\section{Living in the Polymer Age}

\section{Guruswamy Kumaraswamy, Editor}

Materials have always defined the technological limits of civilization. As humanity, we've progressed from the Stone Age to the Iron Age to today's Polymer Age. We consume a staggering amount of polymers - the annual production of synthetic polymers currently exceeds 300 million tons. While this has come with its share of problems, it has also proved to be immensely enabling. To give an India specific example: the humble plastic pouch for milk allows a vast number of Indians to enjoy the success of the White revolution. Imagine the transportation costs for that much milk in heavy, brittle glass bottles. This simply wouldn't be possible - plastic packaging makes it possible to get milk (and other food/drink) to people in a cost effective manner.

The birth of polymers as a science can be traced back to the efforts of pioneers such as Hermann Staudinger and Herman Mark who convinced the world that polymers were truly covalently connected macromolecules. However, it was really the extraordinary chemistry of Wallace Carothers that launched the glorious era of synthetic polymers. Carothers lived and worked in the age when cutting-edge materials science done in industrial laboratories led to world-changing technological innovations. He developed polymers such as nylons and neoprene rubber that represented both fundamental breakthroughs in chemistry and became immediate money spinners for DuPont. In the 1930s, strained relations with Japan resulted in the USA needing to look for alternate sources for silk. The nylon that was developed by Carothers' team at DuPont provided a superior substitute for silk. When nylon stockings were first introduced in the American market on 15 May 1940, the entire stock was sold out before lunch time. In this issue, we pay tribute to this pioneer of polymer materials, with a biography written by Dr Sivaram that combines history

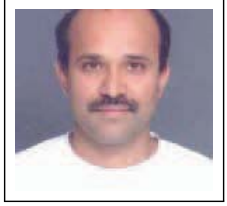

Email: g.kumaraswamy@ncl.res.in 
and science to give us a full appreciation of the milieu in which Carothers worked and to appreciate his immense contributions. This issue also features an article by Prof. Ramakrishnan that initiates the student into the science of polycondensation chemistry - starting with the basics, and building up to illustrate what sort of macromolecules one can build with addition and chain growth techniques.

Carothers' brilliance and extraordinary intuition as a synthetic chemist were supplemented with theoretical understanding developed by his collaborator at DuPont, Paul Flory. It was Carothers who introduced a young Flory to the fascinating world of polymers. Flory then went on to stride polymer science as a colossus, making seminal contributions to almost every aspect of polymers - from reaction kinetics of condensation and addition polymerization, to the structure of polymer chains, to polymer solution thermodynamics, and polymer crystallization. A brief biography of Flory, again, penned by Dr Sivaram is included in this issue of Resonance. Flory has also been featured in Resonance earlier. I would like to refer readers interested in a more detailed biography of Flory to Harold Scheraga's article in the June 2003 issue of Resonance. The classics section features a celebrated article on solution thermodynamics by Flory, where he outlines what is today known as the Flory-Huggins theory.

Unfortunately, the partnership between Carothers and Flory lasted only until Carothers' tragic death in 1937 (by his own hand). Flory went on to win the Nobel Prize for his contributions to polymer science, and one could argue that Carothers would have certainly won the Prize too, had he not died young.

\section{Happy Reading.}

